\title{
The Crude Oil Price Influence on the Brazilian Industrial Production
}

\author{
Andre Assis de Salles, Pedro Henrique Acioli Almeida \\ Polytechnic School, Federal University of Rio de Janeiro, Rio de Janeiro, Brazil \\ Email: as@ufrj.br
}

How to cite this paper: de Salles, A.A. and Almeida, P.H.A. (2017) The Crude Oil Price Influence on the Brazilian Industrial Production. Open Journal of Business and Management, 5, 401-414. https://doi.org/10.4236/ojbm.2017.52034

Received: March 23, 2017

Accepted: April 27, 2017

Published: April 30, 2017

Copyright $\odot 2017$ by authors and Scientific Research Publishing Inc. This work is licensed under the Creative Commons Attribution International License (CC BY 4.0).

http://creativecommons.org/licenses/by/4.0/ (c) (i) Open Access

\begin{abstract}
The oil price is a relevant variable for economic policy makers in countries where this commodity is the main energy source as well as in other countries where crude oil is not the only energy source. The sudden variations in the crude oil price cause direct influence in the national economies bringing changes in foreign trade, investments and productive activities. Therefore, the crude oil market is very important for the economic development. Furthermore, crude oil is directly or indirectly present in all productive activities. This way the crude oil market is related to the industrial production indicators. Many researches aim at establishing the stochastic process that can represent the movements of macroeconomic indicators through the oil price returns or variations that have been done in recent years. The purpose of this work is to study the relationship between crude oil prices and selected industrial production indicators of the Brazilian economy. To do that this work carried out cointegration and causality tests, from VAR estimations, and impulse response analysis. The data used in this study is monthly macroeconomic indicators, mentioned above, and the Brent crude oil type price negotiated in the London Market. All data used is in US\$. The period of the sample used is from January 2002 to October 2015.
\end{abstract}

\section{Keywords}

Oil Price, Industrial Production, Cointegration, Causality, Impulse Response Function

\section{Introduction}

Present in the global energy matrix crude oil is one of the most important energy sources in the world. It is an essential commodity in the global economy. Furthermore, petrochemical and chemistry industries produce or manufacture goods from petroleum, such as fertilizers used in agriculture for food industries. 
Despite the progress in development of renewable energy sources in recent decades, crude oil and their byproducts remain directly or indirectly present in people's lives. Given this relevance, the crude oil price is an important variable for economic policy makers in national economies, where this commodity is the main source of energy as well as in worldwide economies.

The crude oil price movements are influenced by several factors that change randomly, for example, the weather, the available reserves, economic growth, changes in industrial production, political or geopolitical aspects, exchange rate variations, financial speculation, among others, such as sub-prime crisis and the recent fall in oil prices, caused by lower world demand or supply excess, events with large impacts on the crude oil market. These movements in crude oil international markets directly influence the international financial markets and the economy in general, causing changes in foreign trade, investment and all productive activities. Even having many possibilities for renewable energy, crude oil has a significant participation in the Brazilian energy matrix. According to the Brazilian government oil and gas agency, in 2014 crude oil and natural gas together accounted for approximately $44 \%$ of the Brazilian energy matrix. In countries with large reserves, the oil and gas industry often assumes an important role in economic development due to the high investments required for exploration and production of reserves. In Brazil, it was not different, the oil is directly or indirectly present in all sectors, the movement of oil prices is considered a relevant factor in the economic expectations.

Therefore many studies have been developed to verify the influence of oil price movements in economic activities, in economic performance and macroeconomic indicators of national economies, such as gross domestic product rate, industrial production variations and changes of goods and services prices. These studies were conceived in order to establish a stochastic process, which represents the expectation of economic indicators activities of national economies through oil price movements traded in the international market. Moreover, if the impact of oil price return in macroeconomic indicator is understood, it makes the verification of crude oil price impact possible. This allows firms to make predictions taking into consideration the impact on consumption as well as on the price level of their products. On the other hand, financial speculators may use the relation between oil price and macroeconomic indicators estimates to achieve extraordinary profits in the financial market while economic policy makers may use these very estimates to develop public policies that will allow for economic development and growth.

The objective of this work is to study the relationship between crude oil prices traded in the international market and Brazilian industrial production indicators, which are important for economic policies makers, the firms and the economic agents in general. In order to achieve the purpose, the methodological approach of this work comprises tests on time series of these indicators and the oil price to verify causality and cointegration hypotheses and impulse response function, which establish short and long-term relationships between these indi- 
cators and the oil price.

The remainder of this paper was structured as follows. The next section presents studies that deal with the impact of crude oil on macroeconomic indicators on different economies and periods. Section 3 shows the methodological approach description, divided into six distinct parts: stationarity tests, cointegration tests, application autoregressive vector models (VAR) and vector models with error correction (VEC), causality tests and impulse response functions which is determined in the proposed econometric models. Section 4 presents the data used for this study is presented while the results obtained from the test and proposed models are presented in Section 5. The final comments are given in Section 6.

\section{The Literature Review-A Brief}

Given the importance of crude oil for economy, energy matrix and foreign trade, several studies has been done to observe crude oil price shock impacts on macroeconomic variables such as exchange rate, industrial production and trade balance, among others. These studies were carried out using various periods, countries or economic regions using different methodological approaches. Among these studies it must be highlighted the [1] work which, using monthly data between the years 1972 and 1993, searched for the relationships between the oil price and the US exchange rate. For crude oil prices, the West Texas Intermediate (WTI) type real price and deflated price was used, while for the exchange rate, the real exchange rate between the US dollar and fifteen currencies of developed countries was used. The reference [1] study stationarity tests for selected time series, which indicated that these series are integrated of order one, were performed. From the Johansen-Juseilus cointegration test, [1] presented evidence of cointegration between the two series, which show a long-term relationship. Another inference highlighted by [1] is that the crude oil price causes the real exchange rate in the Granger sense, but the reciprocal is not true. The authors argue that the crude oil price has been dominated by shocks, especially in the 70s and early 90s, caused mainly by geopolitical conflicts and not by changes in demand from developed countries. Finally, [1] used a stochastic model with error correction mechanism, which showed significant predictive power for both values inside and outside the sample.

In another important work on this subject, [2] studied the crude oil price shock influences on economic activity and in general price levels, or inflation variation, between 1975 and 2002 in six countries in Asia: South Korea, Philippines, Japan, Malaysia, Singapore and Thailand. Reference [2] test the time series stationary hypothesis through Phillips-Perron and Dickey-Fuller augmented unit root tests, concluding that many series of macroeconomic variables as oil price in local currency and US dollars were integrate of order 1 or stationary in first difference. Using cointegration tests, the authors found no long-term relationship between crude oil prices and macroeconomic variables in the six Asian countries selected. On the other hand, the causality was found in the direction of 
oil prices in economic activities in South Korea, Japan and Thailand, when a structural change in the $80 \mathrm{~s}$ was considered. In other relevant inference, [2] highlighted the existence of the oil price causality in the inflation of the six countries surveyed. In a study that examines the relationship between the global economic activity, the exchange rate and the oil price, [3] used the Kilian index as parameter to measure the level of global activity and an exchange rate index between the US dollar and a basket currency, as a proxy for the exchange rate. Using monthly data, in the period from 1988 up to 2012, of crude oil price, the Kilian index and exchange rate cointegration test and Granger causality test were implemented, and pointed out that the oil price and global activity are cointegrated.

The same occurs between oil prices and exchange rate. Therefore, it can be inferred that there is a long-term relationship between these variables. Another important inference by [3] pointed out that the economic activity index Kilian concerned to Granger oil prices in the international market influenced in the long term, the balance related to cointegration, as in the short term for the activity world economic.

Another relevant study on this subject was conducted by [4] that infer the influence of oil price impact in the international market and the exchange rate of the Russian ruble in the gross domestic product and tax revenues in Russia. The author used quarterly data for the period between 1995 and 2002, a period of major turbulence in the Russian economy, including the debt moratorium declaration in 1998. The reference [4] study used Phillips-Perron and Kwiatkowski Phillips-Schmidt-Shin (KPSS) tests to examine the time series stationary and concluded that time series studied did not have stationary in the level but can be considered integrated of order 1, or stationary at first difference. Reference [4] conducted tests and estimated autoregressive vector models (VAR) concluding that both the exchange rate and the crude oil price, accounting for a half of its exports in 2004, has cointegration with GDP and tax revenue of the country. Reference [4] found evidence that, in the long-term, a $10 \%$ increase in oil prices is associated with a $2.2 \%$ increase in gross domestic product and $4.6 \%$ in tax collection in the country. While an appreciation in real terms the ruble was associated with a $2.7 \%$ fall in income, measured by gross domestic product. Despite the robustness of the statistical results, [4] points out that the parameter estimates should be viewed with reservations, since the analyzed period was short and extremely turbulent.

A survey that should be highlighted is the one by [5], who conducted an extensive review of the literature on the impact of changes in oil prices on macroeconomic variables in different countries and time intervals. Using data regression models panel, the authors studied crude oil and natural gas impacts in industrial production of 18 countries of the Eurozone, such as Germany, France and Italy, between January 2001 and September 2013. Reference [5] concluded that oil prices and natural gas have a negative effect on the industrial production growth and a $1 \%$ change in the oil price and natural gas would cause, respec- 
tively, a decrease in industrial production by $19 \%$ and $18 \%$ in those countries.

\section{Methodological Approach}

Before using stochastic models for time series, it is important to check the violation of basic assumptions. A common assumption in many time series techniques of utmost importance is the stationarity. To test the stationarity of the time series worked in this study, the Dickey-Fuller test (ADF), inserted in the literature by [6], was used. When using non-stationary series, the estimation models of linear regressions, there is the risk of carrying out spurious regressions, that is, with apparent statistical significance of the coefficients of determination but meaningless according to [7]. As noted by [8], considering $Z_{t}$ and $Y_{t}$ two non-stationary time series a linear combination of time series voids the stochastic trends making the new time series stationary which characterizes the two time series as cointegrated. The linear regression model can be estimated as follows:

$$
Z_{t}=\beta_{1}+\beta_{2} X_{t}+e_{t} \Rightarrow e_{t}=Z_{t}-\beta_{1}-\beta_{2} X_{t}
$$

$e_{t}$ is a stochastic term. If, by submitting this stochastic term to a unit root test to test its stationarity, it can be concluded that these two time series are cointegrated and regression estimated between the two variables will not be spurious and, as highlighted by [9], there must be a long-term relationship between them. Reference [7] presents a detailed work about spurious regression when the variables related in regression models are nonstationary. Among the methods proposed in the econometric literature to test the cointegration in this research the Engle-Granger test, described in [10], was used to test the hypothesis of cointegration between the crude oil price and the selected macroeconomic indicators. This test simply consists of applying a unit root test, in this work the ADF test, to verify the stationarity of the stochastic term $e_{t}$ or linear combination of the time series $Z_{t}$ and $Y_{t}$. As the residual term is based directly on cointegrator parameter $\beta_{2}$ and the critical values calculated by Dickey and Fuller are not appropriate, [10] have calculated critical values for the test (see [9]). The two time series cointegration refers to a long-term relationship between the series but nothing prevents imbalances in the short term. Therefore, as pointed out by [9], stochastic term $e_{t}$ can be considered stationary as an equilibrium error and use it to relate the behavior of the two cointegrated time series in the short term with its equilibrium value long term.

In regression models, one variable is the dependent variable and the other the independent variable. However, there are situations where it is not exactly known which of the variables should be treated as a dependent variable. In these situations vector autoregressive models (VAR) can be used.

The VAR models are used to analyze the causal relationship between time series. One can assume the following model in which $Z_{t}$ and $Y_{t}$ are stationary time series, that is, integrated of zero order or I (0):

$$
Y_{t}=\beta_{1}+\beta_{2} Y_{t-1}+\beta_{3} Z_{t-1}+\varepsilon_{1 t}
$$




$$
Z_{t}=\beta_{4}+\beta_{5} Z_{t-1}+\beta_{6} Y_{t-1}+\varepsilon_{2 t}
$$

In the equations described above, each variable depends on its value with a lag and another lagged variable. This equation system characterizes a vector autoregressive model (VAR) and when using only one lag for each of the independent variables it becomes a VAR (1), or vector autoregressive model of order 1 . The above can be used directly if the two time series $Z_{t}$ and $Y_{t}$ are stationary. However, if the time series are I (1) and are not cointegrated one should use the VAR with the first difference operators of these variables. Therefore, the equation system can be described as follows:

$$
\begin{aligned}
& \Delta Y_{t}=\beta_{1}+\beta_{2} \Delta Y_{t-1}+\beta_{3} \Delta Z_{t-1}+\varepsilon_{1 t} \\
& \Delta Z_{t}=\beta_{4}+\beta_{5} \Delta Z_{t-1}+\beta_{6} \Delta Y_{t-1}+\varepsilon_{2 t}
\end{aligned}
$$

As all the above variables are stationary, one can estimate the model normally. In general, if the two time series are integrated of order $n$, one can use that number of differences in the model described above.

A large number of lags can be a problem for small samples, since the estimate of all parameters consume many freedom degrees of a VAR model. Furthermore it must be highlighted that if the variables are integrated of order 1 and therefore not stationary, but are cointegrated the equation system should be modified to take into account this long-term relationship. This modified version is known as vector model with error correction or VEC model. Thus, if two time series are integrated of order 1 and cointegrated they can be related in the following equation:

$$
Z_{t}=\beta_{1}+\beta_{2} Y_{t}+\mu_{t}
$$

By definition, since they are two cointegrated time series the stochastic term $\mu_{t}$ presents stationary behavior. The VEC model is used to estimate the system of equations below where all the terms are stationary, as in the VAR model below:

$$
\begin{aligned}
\Delta Y_{t} & =\alpha_{1}+\alpha_{2} \mu_{t-1}+\varepsilon_{1 t} \\
\Delta Z_{t} & =\alpha_{3}+\alpha_{4} \mu_{t-1}+\varepsilon_{2 t}
\end{aligned}
$$

Using the values of residual term lagged $\mu_{t-1}$, the VEC model can be represented as follows:

$$
\begin{aligned}
& \Delta Y_{t}=\alpha_{1}+\alpha_{2}\left(Z_{t-1}-\beta_{1}-\beta_{2} Y_{t-1}\right)+\varepsilon_{1 t} \\
& \Delta Z_{t}=\alpha_{3}+\alpha_{4}\left(Z_{t-1}-\beta_{1}-\beta_{2} Y_{t-1}\right)+\varepsilon_{2 t}
\end{aligned}
$$

This system can be written in following form:

$$
\begin{aligned}
& Y_{t}=\alpha_{1}-\left(\alpha_{2} \beta_{2}-1\right) Y_{t-1}-\alpha_{2} \beta_{1}+\alpha_{2} Z_{t-1}+\varepsilon_{1 t} \\
& Z_{t}=\alpha_{3}+\left(\alpha_{4}+1\right) Z_{t-1}-\alpha_{4} \beta_{1}-\alpha_{4} \beta_{2} Y_{t-1}+\varepsilon_{2 t}
\end{aligned}
$$

In the regression model above the parameters $\alpha_{2}$ and $\alpha_{4}$ are known as error correction coefficients, since they show the response magnitude of $Z_{t}$ and $Y_{t}$ variables given a variation of the residual term $\mu_{t-1}$. To ensure stability, error correction mechanism coefficients must respect the following restrictions: $\alpha_{2} \in[0,1)$ and $\alpha_{4} \in(-1,0]$. To understand this error correction effect and the importance 
of the above restrictions, one can assume a situation in which the cointegrating regression shows a positive stochastic term in an accomplishment. These conditions guarantee that for a positive stochastic term, the $\Delta Y_{t}$ variation is positive and the $\Delta Z_{t}$ negative restoring the balance described by the cointegration. The lower modules of these parameters ensure that a system of equations does not present an explosive behavior.

Although the analysis of regression models describe the dependence of a variable in relation to the other, the existence of a regression does not necessarily imply a Granger causality. In time series analysis a recurring issue is the existence and direction of causality between two variables. That is, the change in one variable causes a change in the other. To investigate the causality between the variables studied in this work we used the Granger causality test. One can assume two stationary time series $Z_{t}$ and $Y_{t}$, for which there is interest in knowing if there is any causality between them. To do this, one can use the VAR with $n$ lags as shown in the equation system below.

$$
\begin{aligned}
& Y_{t}=\sum_{i=1}^{n} \alpha_{i} Y_{t-i}+\sum_{j=1}^{n} \beta_{j} Z_{t-j}+\varepsilon_{1 t} \\
& Z_{t}=\sum_{k=1}^{n} \gamma_{k} Y_{t-k}+\sum_{l=1}^{n} \delta_{l} Z_{t-l}+\varepsilon_{2 t}
\end{aligned}
$$

The VAR model described above can be extended to more variables increasing the number of variables and equations in the model. This model relates the value of the variables with their lagged values and the lagged values of the other variable. There are four possible scenarios. The first scenario would be one in which the estimated coefficients of the first lag $Z_{t}$ regression were jointly different from zero, and the estimated coefficients of the second lag $Y_{t}$ regression were jointly close to zero. In this case, there is a unidirectional causality from $Y_{t}$ to $Z_{t}$. The $Z_{t}$ lagged values predict the variable $Y_{t}$ behavior, but lagged values of $Y_{t}$ do not contribute to predict the $Z_{t}$ behavior. In an unidirectional causality scenario in the reverse direction, there is the situation where the sum of the parameters $\beta_{j}$ is zero and the sum of the parameters $\gamma_{k}$ is nonzero. A third possible scenario is the existence of bilateral causality: $Y_{t}$ causes $Z_{t}$ as well as $Z_{t}$ causes $Y_{t}$. This scenario is characterized by the sum of parameters $\beta_{j}$ and the sum of the parameters $\gamma_{k}$ that are both different from zero. Finally, when the above lagged values are all jointly equal to zero, that is, there is non-association between the variables $Y_{t}$ and $Z_{t}$. The null hypothesis of all the lagged coefficients being jointly equal to zero in the Granger causality test is tested by F statistics.

As noted by [11], the study of impulse response functions has the purpose of understanding the effects of random shocks in a time series. The impulse response function allows to verify the behavior of a variable when the other, related to in the autoregressive vector model, suffers a shock or an impulse at a time $t$ which propagates in future moments, for more details see [12]. A time series described by the autoregressive model with a lag is shown below:

$$
Y_{t}=\rho Y_{t-1}+v_{t}^{y}
$$

Assuming the initial zero value to a time series, this study tries to infer how 
the values in this time series would behave given a unit shock at the start of the series, without other shocks. If $\rho=1$, there is a unit root process and therefore the time series is no stationary. It should also be noted that in this specific case, the process would have infinite memory: the shock effect never scatters. However, when a value for the parameter is lower than a unit, the variable initially fully incorporates the shock value but returns to the null value, using the vector autoregressive model (VAR) described above in the following form:

$$
\begin{aligned}
& Y_{t}=\sum_{i=1}^{n} \alpha_{i} Y_{t-i}+\sum_{j=1}^{n} \beta_{j} Z_{t-j}+v_{t}^{y} \\
& Z_{t}=\sum_{k=1}^{n} \gamma_{k} Y_{t-k}+\sum_{l=1}^{n} \delta_{l} Z_{t-l}+v_{t}^{z}
\end{aligned}
$$

In the model above two possible shocks, one for each variable, are found. There are two response functions related to each shock, one for each variable. In total there are four response functions related to the VAR model and therefore it is possible to study the impact of a variable shock in the variable values itself and on the other variable values.

\section{The Data-Sample Used}

In addition to the crude oil price in the international market, the primary data used in this study refers to Brazilian industrial production indicators. The monthly crude oil prices used in this study were the Brent type crude oil prices traded in US dollars in London and collected from the EIA, the North American energy agency, for the period from January 2002 to October 2015. Indicators of industrial production, the industrial production indicators, released monthly by the Brazilian Statistical Institute (IBGE), were collected. According the IBGE these indicators are calculated by monitoring the production of about 830 products in 3700 industrial places. The index is released according to the use of industrial production categories, namely: 1) Overall Industry; 2) Consumer Goods; 3) Consumer Durable Goods; 4) Mining and Quarrying; 5) Manufacturing; 6) Capital Goods; 7) Intermediate Goods; 8) Semi and Non-durable Consumer Goods; and 9) Construction Inputs. The data used in this study were monthly industrial production indices by category of use, from January 2002 to October 2015, except for the construction inputs index, available only since January 2012.

To characterize the time series used in this study, statistical summaries were performed. These summaries are intended to observe the average, the dispersion, the maximum, the minimum and the median values. Besides that the summary presents the skewness and kurtosis coefficients to verify the normality hypothesis, which is complementary with the Jarque-Bera (JB) normality hypothesis test. To characterize the time series selected, the stationarity hypothesis test, which is inserted in the summary, was performed.

As noted above, the non-stationarity is a recurrent problem in the study of time series. Therefore, additionally, the logarithmic returns of all the studied time series were calculated. The statistical summaries and stationary tests for all returns or variation of used time series was also performed. These returns were calculated using the following formula: 


$$
\text { Return } X_{t}=\ln \left(\frac{X_{t}}{X_{t-1}}\right)
$$

In the studied period, Brent crude oil price fluctuated between 19.4 and 132.7 US dollars per barrel, with average and median close to 70 US dollars. The price of Brent crude oil showed: asymmetry coefficient close to zero; a low coefficient of kurtosis, with a value of about 1.8; and a high volatility, measured by standard deviation of about 31.2 US dollars per barrel. The Brent oil price had higher values for their standard deviations when compared with their respective averages. The skewness and kurtosis coefficients mentioned above show that these time series differ from a normal distribution time series, which is confirmed through the Jarque Bera test.

Table 1 above shows the industrial production indicators time series statistical summaries. As expected, the industrial production time series have averages and medians close to 100 , the base value is 2012. As shown in Table 1 , the industrial production of Capital Goods Index had the lowest average, with a value of 88.5, while the number of Construction Inputs Index showed the highest average, with a value of 96.2. The standard deviations of industrial production indicators present a wide range of values. The standard deviation of the industrial production of Capital Goods indicator, for example, is more than double of the Intermediate Goods and Construction Inputs indicators. The industrial production of Capital Goods has also the highest maximum, of about 127.1, while the industrial production of Consumer Durable Goods has the lowest minimum, of about 48.5. The industrial production time series kurtosis and asymmetry coefficients that presented different values demonstrate varied behaviors from the

Table 1. Brazilian Industrial Production Indicators: 1) Overall Industry; 2) Consumer Goods; 3) Consumer Durable Goods; 4) Mining and Quarrying; 5) Manufacturing; 6) Capital Goods; 7) Intermediate Goods; 8) Semi and Non-durable Consumer Goods; 9) Construction Inputs.

\begin{tabular}{cccccccccc}
\hline $\begin{array}{c}\text { Industrial } \\
\begin{array}{c}\text { Production } \\
\text { Indicator }\end{array}\end{array}$ & $(1)$ & $(2)$ & $(3)$ & $(4)$ & $(5)$ & $(6)$ & $(7)$ & $(8)$ & $(9)$ \\
\hline Mean & 93.7 & 92.6 & 87.3 & 89.5 & 93.9 & 88.2 & 95.5 & 94.3 & 95.8 \\
Median & 93.8 & 93.4 & 89.8 & 91.6 & 93.4 & 88.5 & 95.9 & 94.3 & 96.2 \\
Maximum & 112.6 & 116.3 & 119.3 & 113.7 & 113.7 & 127.1 & 111.4 & 116.2 & 110.9 \\
Minimum & 69.7 & 67.4 & 48.5 & 58.9 & 70.4 & 50.4 & 74.8 & 70.5 & 81.1 \\
Std Devition & 10.0 & 11.4 & 17.8 & 13.3 & 10.1 & 20.5 & 8.2 & 10.2 & 8.5 \\
Skewness & -0.2 & -0.2 & -0.3 & -0.4 & -0.2 & -0.1 & -0.3 & -0.1 & -0.3 \\
Kurtosis & 2.3 & 2.4 & 2.2 & 2.0 & 2.3 & 1.9 & 2.5 & 2.4 & 1.9 \\
JB test & 4.96 & 3.54 & 7.76 & 9.99 & 4.51 & 9.12 & 3.99 & 2.53 & 2.46 \\
p-value & 0.08 & 0.17 & 0.02 & 0.01 & 0.11 & 0.01 & 0.14 & 0.28 & 0.29 \\
ADF & -2.13 & -1.80 & -1.82 & -1.30 & -2.11 & -1.92 & -2.69 & -1.77 & -2.72 \\
$p$-value & 0.23 & 0.38 & 0.37 & 0.63 & 0.24 & 0.32 & 0.08 & 0.39 & 0.08 \\
lags & 13 & 13 & 12 & 12 & 13 & 13 & 12 & 13 & 0 \\
\hline
\end{tabular}


normal distribution and the JB tests applied confirming it. The results of the JB normality tests indicate that the normality hypothesis should not be accepted for the Consumer Durable Goods, Mining and Quarrying and Capital Goods industrial production indicators time series. As can be seen in Table 2 ahead the monthly returns of Brazilian industrial production time series have low values of mean and medians, less than $1 \%$. Noteworthy are the high modulus of the minimum return of industrial production of Capital Goods, which reached $-39 \%$, and the maximum return of industrial production of Consumer Durable Goods, of about $+35 \%$. The industrial production of Consumer Durable Goods variations also had the highest standard deviation, with a value of $12.5 \%$. The kurtosis and asymmetry coefficients of the industrial production indicator variationsor returns showed very different values. Only Overall Industry, Mining and Quarrying and Intermediate Goods indicators showed positive skewness coefficients. The kurtosis coefficients showed values of around three, which is the value of a normal distribution. According to the JB tests, the null hypothesis of normality can not accept for the Consumer Durable Goods and Capital Goods series only.

As expected, the result of the augmented Dickey-Fuller stationarity test (ADF) for the Brent crude oil price time series point out for non-acceptance of the stationarity hypothesis. The same applies to all nine series of industrial production indicators, that is, the hypothesis stationarity can not be accepted. For industrial production indicator variations, the results show no rejection of stationarity hypothesis for most of the series. Thus, considering the return series or variations of selected macroeconomic indicators, the stationarity hypothesis can not be accepted only for the time series returns of Manufacturing, Capital Goods and

Table 2. Brazilian Industrial Production Indicator Variations: 1) Overall Industry; 2) Consumer Goods; 3) Consumer Durable Goods; 4) Mining and Quarrying; 5) Manufacturing; 6) Capital Goods; 7) Intermediate Goods; 8) Semi and Non-durable Consumer Goods; 9) Construction Inputs.

\begin{tabular}{cccccccccc}
\hline $\begin{array}{c}\text { Industrial } \\
\begin{array}{c}\text { Production } \\
\text { Indicator }\end{array}\end{array}$ & $(1)$ & $(2)$ & $(3)$ & $(4)$ & $(5)$ & $(6)$ & $(7)$ & $(8)$ & $(9)$ \\
\hline Mean & 0.002 & 0.002 & 0.002 & 0.002 & 0.002 & 0.002 & 0.002 & 0.002 & 0.002 \\
Median & 0.000 & 0.008 & 0.011 & 0.001 & 0.002 & 0.005 & -0.002 & 0.007 & 0.005 \\
Maximum & 0.166 & 0.180 & 0.350 & 0.159 & 0.170 & 0.233 & 0.148 & 0.160 & 0.126 \\
Minimum & -0.196 & -0.188 & -0.470 & -0.138 & -0.200 & -0.317 & -0.176 & -0.163 & -0.177 \\
Std Devition & 0.065 & 0.076 & 0.125 & 0.056 & 0.067 & 0.098 & 0.059 & 0.070 & 0.072 \\
Skewness & 0.077 & -0.088 & -0.379 & 0.055 & -0.030 & -0.390 & 0.254 & -0.076 & -0.424 \\
Kurtosis & 3.143 & 2.732 & 4.069 & 2.998 & 3.246 & 3.897 & 3.059 & 2.298 & 2.608 \\
JB test & 0.30 & 0.70 & 11.82 & 0.08 & 0.44 & 9.71 & 1.80 & 3.54 & 1.64 \\
-value & 0.86 & 0.70 & 0.00 & 0.96 & 0.80 & 0.01 & 0.41 & 0.17 & 0.44 \\
ADF & -2.64 & -3.90 & -2.49 & -2.23 & -3.07 & -2.22 & -3.97 & -2.28 & -8.98 \\
p-value & 0.087 & 0.003 & 0.119 & 0.196 & 0.031 & 0.201 & 0.002 & 0.180 & 0.000 \\
lags & 13 & 11 & 12 & 12 & 11 & 13 & 11 & 13 & 0 \\
\hline
\end{tabular}


Semi and Non-durable Goods industrial production.

\section{Results Obtained}

As described earlier, the Engle-Granger test to examine the cointegration between crude oil prices and industrial production indicator time series studied here was performed. In the Engle-Granger cointegration tests, two regressions were performed for each industrial production indicators and crude oil price time series. In the first regression variable one variable is dependent and the other is independent, in the second regression the dependence changes. The cointegration hypothesis is not rejected only if both regression models indicate that cointegration hypothesis should not be rejected. If they are not, one should reject the null hypothesis and conclude that the series are cointegrated and therefore, there is a long-term relationship between them.

Table 3 shows the cointegration test results. It is possible to infer, at the $10 \%$ level of significance, that the Brent crude oil price is cointegrated with the Overall Industry, Intermediate Goods, Manufacturing and Construction Inputs industrial production indicators. It must be highlighted that the industrial production of capital goods and semi-durable and nondurable goods are integrated in more than one order, that is, nonstationary for difference. It would be inappropriate to use them in Engle-Granger cointegration tests. For those time series that showed no cointegration the VAR models are used to observe the behavior of time series returns studied here and the significance of crude oil price on them. These models were built using the log returns or the log variations of the time series studied. As shown in Table 1 the macroeconomic indicator time series do not present stationarity. This occurs also with the crude oil price. The lag numbers for all VAR model estimated were determined using the Akaike criteria selection model limited up to 12 lags or 12 months. The values of Akaike criteria for various lags can be observed in Table 1, in which the lag numbers for each model are indicated.

The Granger causality test is determined through these bivariate VAR models estimated with the Brent crude oil price returns and industrial production indicators selected for this work, that is, these tests verify if the returns after Brent

Table 3. Cointegration test results.

\begin{tabular}{|c|c|c|c|c|}
\hline \multirow{2}{*}{$\begin{array}{l}\text { Industrial } \\
\text { Production } \\
\text { Indicator }\end{array}$} & \multicolumn{2}{|c|}{$\begin{array}{c}\text { Variable } \\
\text { Dependent Indicator }\end{array}$} & \multicolumn{2}{|c|}{$\begin{array}{c}\text { Variable } \\
\text { Dependent Oil Price }\end{array}$} \\
\hline & ADF Test & (p-value) & ADF Test & (p-value) \\
\hline Overall Industry & -3.076 & 0.099 & -2.429 & 0.316 \\
\hline Consumer Durable Goods & -2.683 & 0.211 & -2.870 & 0.151 \\
\hline Intermediate Goods & -3.613 & 0.027 & -2.115 & 0.470 \\
\hline Mining and Quarrying & -1.129 & 0.876 & -2.308 & 0.373 \\
\hline Manufacturing & -3.153 & 0.084 & -2.370 & 0.343 \\
\hline Construction Inputs & -4.474 & 0.004 & -2.884 & 0.161 \\
\hline
\end{tabular}


crude oil price used in the model cause the contemporary variations of the variables studied. As described earlier the Granger causality hypothesis test consists in verifying if the coefficients of the VAR model are jointly close to zero. It can be inferred that the Brent crude oil price returns, at a $10 \%$ level of significance, cause the industrial production time series variations for durable consumer goods, intermediate and mining industry goods. Therefore, it is possible to infer that at a $10 \%$ level of significance that the Brent crude oil price returns should explain the Brazilian industrial production indicators studied.

To obtain impulse response functions that permit to observe the oil price return shocks repercussion in the Brazilian industrial production indicators, VAR models were proposed. As mentioned in the methodological approach each VAR model estimated has four impulse response functions associated, that are presented from Figures 1-3 shown below. The solid lines show the dependent variable expected behavior before a shock while the dashed red lines show the error average of response expectations interval.

In Figure 1 the VAR model impulse response function of Brent oil price return and the industrial production index for durable consumer goods variations are shown. This index respond quickly to a shock of about $8 \%$ in crude oil prices returns with a $1.5 \%$ positive variation but it was dissipated in around 3 months' time. Figure 2 and Figure 3 present the VAR model impulse response function for Mining and Quarrying industrial production and Intermediate Goods industrial production indices variations.

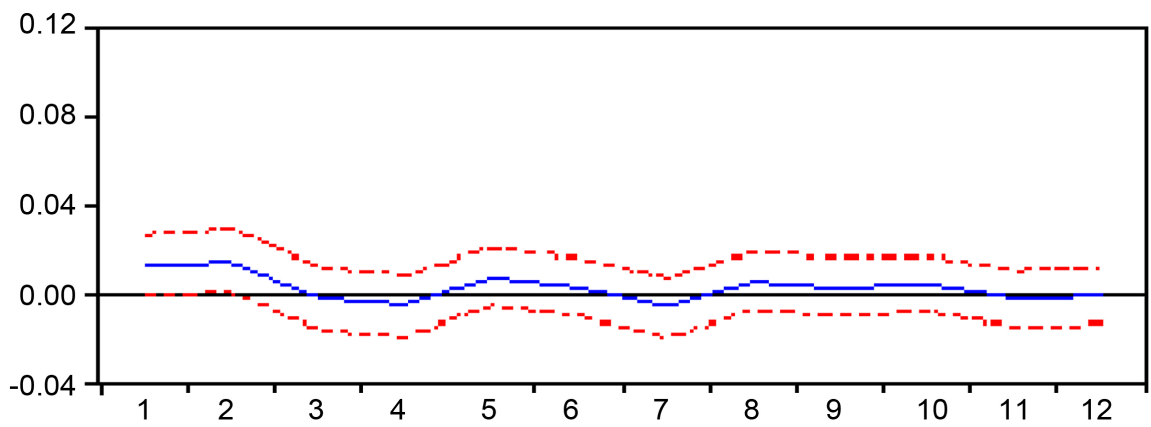

Figure 1. IRF-oil return to consumer durable goods industrial production indicator variation.

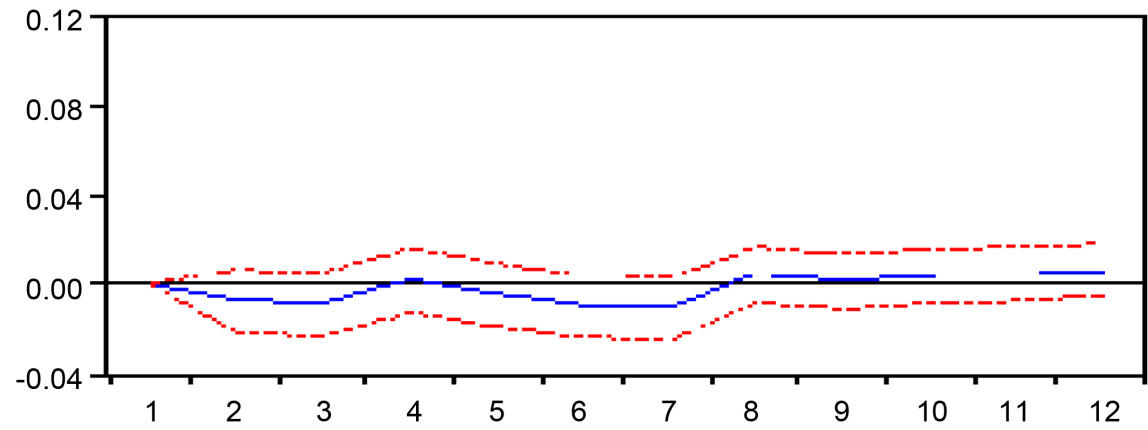

Figure 2. IRF-oil return to mining and quarrying industrial production indicator variation. 


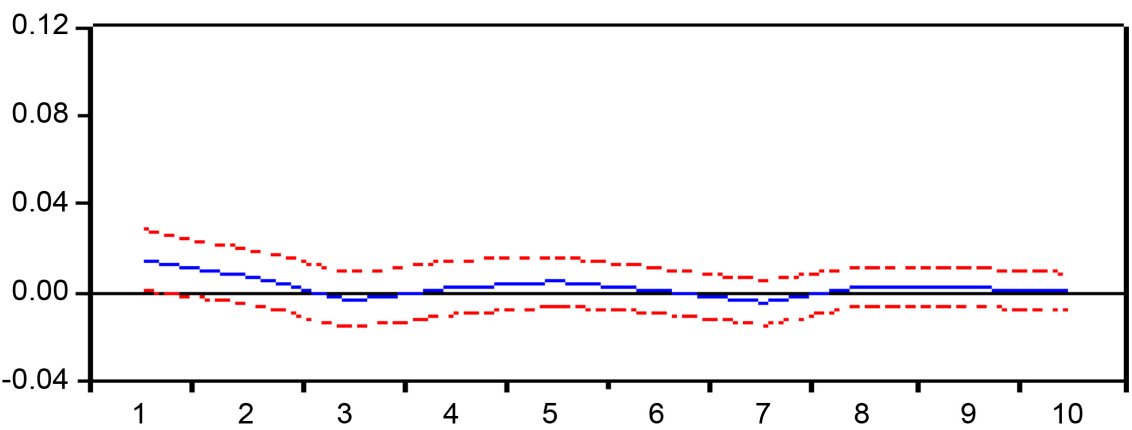

Figure 3. IRF-oil return to intermediate goods industrial production indicator variation.

Both have little relevance responses to shocks in the oil price returns. The Mining and Quarrying industrial production index show a response of $0.05 \%$ to a crude oil price returns impact with lagged about three months, to a crude oil price return shock of around $8 \%$, in which the Brent oil price return was quickly dissipated. The Brent oil price returns has no significant response to shocks on the Mining and Quarrying industrial production index variations while each intermediate goods production index variations have an response about $1 \%$ to $8 \%$ shock in oil prices return, and also this response quickly was dissipated.

\section{Conclusion and Final Comments}

This study aimed to test hypothesis for establishing short and long-term relationships between industrial production indicators of the Brazilian economy and crude oil price in the international market.

It must be noted that industrial production indicators of the Brazilian economy time series stationary test conducted indicated that the industrial production of Capital Goods, Consumer Goods as well as Semi and Non-durable Consumer Goods time series are integrated in an order greater than unity. Thus, the stationarity assumption can not be accepted for these time series, hindering the work done here. Another problem to be observed concerns the period studied. In the sample interval, fuel prices in Brazil did not fluctuate freely once the Brazilian government authorities imposed a fuel price control seeking to contain inflationary pressures, that is, in an attempt to control prices in the economy. Through the cointegration tests, it can be inferred that there is evidence of a long-term relationship between Brent crude oil price and indices of Overall Industry, Intermediate Goods, Manufacturing and Construction Inputs. The causality tests point out that the Brent oil price returns should allow the understanding of industrial production sectors variations in the Brazilian economy, namely: the Consumer Durable Goods, the Intermediate Goods and the Mining and Quarrying industry. Finally, the impulse response functions from the proposed autoregressive vector models were obtained.

Therefore, the objectives of this study were achieved and the results can be taken into account in the estimation of short and long-term relationships to explain industrial production indicators of the Brazilian economy through changes in oil prices in the international market. 
Thus, the preparation of studies seeking to establish appropriate models for the prediction of the Brazilian economy leading indicators, which can provide alternatives to formulate key economic policies for the Brazilian economic growth, is what is suggested for future works that may continue this research.

\section{References}

[1] Amano, R.A. and van Norden, S. (1998) Oil Prices and the Rise and Fall of the US Real Exchange Rate. Journal of International Money and Finance, 17, 299-316.

[2] Cuñado, J. and Gracia, F. (2005) Oil Prices, Economic Activity and Inflation: Evidence for Some Asian Countries. The Quarterly Review of Economics and Finance, $45,65-83$.

[3] Yanan, H., Wang, S. and Lai, K.K. (2010) Global Economic Activity and Crude Oil Prices: A Cointegration Analysis. Energy Economics, 32, 868-876.

[4] Rautava, J. (2014) The Role of Oil Prices and the Real Exchange Rate in Russia's Economy: A Cointegration Approach. Journal of Comparative Economics, 32, 315 327.

[5] Bayar, Y. and Kilic, C. (2014) Effects of Oil and Natural Gas Prices on Industrial Production in the Eurozone Member Countries. International Journal of Energy Economics and Policy, 4, 238-247.

[6] Dickey, A.D. and Fuller, A.W. (1979) Distribution of the Estimators for Autoregressive Time Series with a Unit Root. Journal of the American Statistical Association, 74, 427-431.

[7] Granger, C. and Newbold, P. (1976) $\mathrm{R}^{2}$ and the Transformation of Regression Variables. Journal of Econometrics, 4, 205-210.

[8] Cochrane, J.H. (1997) Time Series for Macroeconomics and Finance. University of Chicago, Chicago. http://www.bseu.by/russian/faculty5/stat/docs/4/Cochran,TimeSeries.pdf

[9] Gujarati, D. (2004) Basic Econometrics. 4th Edition, McGraw-Hill Companies, New York.

[10] Engle, R.F. and Granger, C.W. (1987) Co-Integration and Error Correction: Representation, Estimation and Testing. Econometrica, 55, 251-276. https://doi.org/10.2307/1913236

[11] Hill, C. Rand Griffiths, E.W. (2008) Principles of Econometrics. 4th Edition, John Wiley \& Sons, New York.

[12] Enders, W. (2009) Applied Econometric Time Series. 3th Edition, John Wiley \& Sons, New York. 
Submit or recommend next manuscript to SCIRP and we will provide best service for you:

Accepting pre-submission inquiries through Email, Facebook, LinkedIn, Twitter, etc. A wide selection of journals (inclusive of 9 subjects, more than 200 journals)

Providing 24-hour high-quality service

User-friendly online submission system

Fair and swift peer-review system

Efficient typesetting and proofreading procedure

Display of the result of downloads and visits, as well as the number of cited articles Maximum dissemination of your research work

Submit your manuscript at: http://papersubmission.scirp.org/

Or contact ojbm@scirp.org 